\title{
Long-term Results of Low Grade Appendiceal Mucinous Neoplasm (LAMN): A Retrospective Analysis of 24 Patients
}

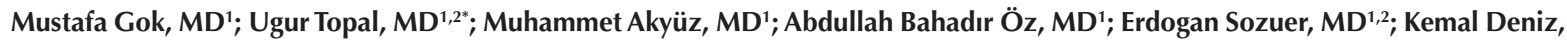 \\ $\mathrm{MD}^{3}$
}

'Department of General Surgery, Erciyes University Medical Faculty, Melikgazi, Kayseri, Turkey

${ }^{2}$ Department of Surgical Oncology, Erciyes University Medical Faculty, Melikgazi, Kayseri, Turkey

${ }^{3}$ Department of Pathology, Erciyes University Medical Faculty, Melikgazi, Kayseri, Turkey

\begin{abstract}
Background: Appendix tumors are rare tumors found in the gastrointestinal tract, observed at a rate of about $0.2 \%-0.3 \%$. Our aim in this study was to present the clinicopathological classification, treatment and long-term prognosis of patients with low grade appendiceal mucinous neoplasm (LAMN)

Methods: Patients who underwent surgery in the Erciyes University Department of (Kayseri, Turkey), Department of General Surgery between December 2010 and December 2018, and who had LAMN as a result of pathology were included in our study. Demographic data, clinical and pathological features of the disease, their treatment and follow-up results after treatment were reviewed retrospectively.

Results: We included 24 patients in the study. Of these patients, 10 (41.6\%) were male. The mean age distribution was $56.4 \pm 20.3$ (21-91) years. Appendectomy was performed in 14 patients, and additional organ resections were performed in 8 patients. The most common symptom at the time of presentation was abdominal pain $(79.1 \% ; 95 \% \mathrm{Cl}, 58.3-91.7)$. The most common preliminary diagnosis in the preoperative period was acute appendicitis $(50 \% ; 95 \% \mathrm{Cl}, 29.2-70.8)$. Mean postoperative hospitalization time was $7.4 \pm 7.96(2-31)$ days. On pathological examination, appendectomy resection margins were positive in two patients. The mean (median) postoperative follow-up was $31.25 \pm 23.9$ (27) (1-90) months. One-year survival was $91.6 \%$, and 5 -year survival was $83.3 \%$. Recurrence was detected in three patients during the follow-up period.

Conclusion: If appendix mucinous neoplasia ( $\mathrm{AMN}$ ) is suspected in patients undergoing surgery with an initial diagnosis of acute or plastron appendicitis, care should be taken to remove the lesion without perforation. Pseudomyxoma peritonei, which may develop as a result of perforation, is associated with recurrence and decreased survival.

Keywords: Appendix, Low grade mucinous neoplasm, Mucinous tumor, Pseudomyxoma peritonei

Cite this article as: Gok M, Topal U, Akyüz M, Öz AB, Sozuer E, Deniz K. Long-term results of low grade appendiceal mucinous neoplasm (LAMN): a retrospective analysis of 24 patients. Arch Iran Med. 2021;24(8):615-621. doi: 10.34172/aim.2021.87
\end{abstract}

Received: March 18, 2020, Accepted: September 27, 2020, ePublished: August 1, 2021

\section{Introduction}

Appendix tumors are one of the rare tumors seen in the gastrointestinal tract, and their frequency is reported at a rate of $0.2 \%-0.3 \%$. Mucinous tumors constitute approximately one third of all epithelial tumors of the appendix. They are more common in the sixth decade and in women. ${ }^{1}$

Low grade appendiceal mucinous neoplasms (LAMN) are lesions that grow characteristically slowly but may cause the development of pseudomyxoma peritonei (PMP) with mucinous deposits that are limited to the periappendicular region or spread throughout the peritoneum. However, they usually do not spread beyond the peritoneum and do not show lymph node metastasis. $^{2}$ In LAMN, macroscopically, the appendix is often enlarged with mucin, and may sometimes look normal. Mucin deposits can be found on the thinned wall or serosal surface depending on rupture. The terminology and classification in mucinous tumors of the appendix are a highly controversial subject. Misdraji coined the term "low-grade appendiceal mucinous neoplasm (LAMN)" in 2003 as a description of confined appendiceal neoplasms with or without pushing invasion. ${ }^{3}$

A consensus was established in 2016 by the International Peritoneal Surface Oncology Group (PSOGI) to use a common terminology and classification for both mucinous tumors of the appendix and associated PMP. LAMNs were defined by the PSOGI as a mucinous neoplasm with low-grade cytology and any of the following properties: fibrosis of the submucosa, loss of the lamina propria and muscularis mucosae, a "pushing" pattern of growth into the wall imparting an expansile or diverticulum-like growth, dissection of acellular mucin into the wall, or mucin and/or neoplastic mucinous epithelium outside the wall of the appendix. ${ }^{4}$

Our aim in this study was to present the 
clinicopathological classification, treatment and longterm prognosis of patients with LAMN.

\section{Patients and Methods}

Patients who underwent appendectomy, those who were operated on with an initial diagnosis of ovarian mass and who underwent appendectomy and whose pathology result showed LAMN result in the Erciyes University Faculty of Medicine Department of General Surgery between December 2010 and December 2018 were included in our study. Patients under the age of 18 and two patients who did not come to their oncological follow-up visits were excluded from the study because of missing data. Patient information was evaluated retrospectively. Demographic features of the patients, preoperative clinical preliminary diagnosis, the surgical procedure, intraoperative macroscopic view of the appendix, presence of PMP, appendectomy resection margins, non-appendix spread status, post-op hospitalization time (days), 1- and 5-year results after discharge, follow-up time, survival, and recurrence were evaluated.

LAMNs were defined according to PSOGI. ${ }^{4}$ The institution where the study was conducted is a university tertiary hospital for a population of five million. The patients were followed up every 3 months during the first year, every 6 months during the second year, and annually after 2 years. Survival data were obtained from patient follow-up and through the population registration system. The definition of disease-free survival was the time from randomization to recurrence of tumor or death. 30-day readmission was defined as unplanned readmissions that happen within 30 days of discharge from the index hospitalization. Recurrence was defined as the recurrence of the disease radiologically and pathologically in patients undergoing curative treatment. Exitus was defined as the death of the patient, regardless of relation to oncological causes.

\section{Statistical Analysis}

For statistical analysis of the data obtained in this study, the SPSS v. 15.0 package program was used (SPSS Inc, Chicago, Illinois, USA). Continuous data are summarized as mean and standard deviation, while categorical data are summarized in numbers and percentages. Log rank and Kaplan-Meier tests were used for survival analysis.

\section{Results}

We included 24 patients in the study. Ten of the patients were male $(41.6 \%)$ and 14 were female (59.4\%). The mean age was $56.4 \pm 20.3(21-91)$ years and the mean BMI was $23.6 \pm 1.8(20-27)$. Demographic data of the patients are summarized in Table 1.

The most common symptom at presentation was abdominal pain. The most common preliminary diagnosis in the preoperative period was acute appendicitis. The most common imaging finding in the preoperative period was suggestive of acute appendicitis (Table 2).

Sixteen patients underwent emergency and eight underwent elective surgery. All patients included in the study underwent laparotomy, including one patient who initially underwent laparoscopic surgery but then was converted to laparotomy when an unexpected diagnosis was made during the operation. In the postoperative period, wound infection developed in two patients and pneumonia in one patient. These patients were followed up with daily dressing and medical treatment. The mean postoperative hospitalization duration was $7.4 \pm 7.96(2-31)$ days. No patients expired in the

Table 1. Demographic Characteristics and Comorbidities of the Patients

\begin{tabular}{|c|c|c|c|c|}
\hline \multirow{2}{*}{ Variable } & \multirow{2}{*}{\multicolumn{2}{|c|}{ Mean \pm SD $($ Min-Max $)$}} & \multicolumn{2}{|c|}{$95 \%$ Confidence Interval } \\
\hline & & & Lower & Upper \\
\hline Age & 56 & $-91)$ & 48.29 & 64.37 \\
\hline BMI & 23 & $-27)$ & 22.91 & 24.33 \\
\hline \multirow[t]{2}{*}{ ASA score } & \multicolumn{2}{|c|}{$1.8 \pm 1.07(1-4)$} & 1.45 & 2.25 \\
\hline & $\mathbf{N}$ & $(\%)$ & & \\
\hline \multicolumn{5}{|l|}{ Gender } \\
\hline Male & 10 & 41.7 & 25.0 & 62.5 \\
\hline Female & 14 & 58.3 & 37.5 & 75.0 \\
\hline \multicolumn{5}{|l|}{ Comorbidities } \\
\hline Hypertension & 6 & 25) & & \\
\hline Coronary artery disease & 4 & $(16.6)$ & & \\
\hline Diabetes mellitus & 8 & (33) & & \\
\hline Chronic obstructive pulmonary disease & 8 & (33) & & \\
\hline Heart failure & 1 & $(4.16)$ & & \\
\hline Chronic kidney failure & 1 & $(4.16)$ & & \\
\hline B-cell lymphoma & 1 & $(4.16)$ & & \\
\hline
\end{tabular}

BMI, body mass index. 
Table 2. Main Symptom of the Patients at the Time of Presentation, Preoperative Diagnoses, Preoperative Imaging Diagnosis

\begin{tabular}{|c|c|c|c|c|}
\hline \multirow[t]{2}{*}{ Variable } & \multirow[t]{2}{*}{$\mathbf{N}$} & \multirow[t]{2}{*}{$(\%)$} & \multicolumn{2}{|c|}{$\begin{array}{c}95 \% \text { Confidence } \\
\text { Interval } \\
\end{array}$} \\
\hline & & & Lower & Upper \\
\hline \multicolumn{5}{|l|}{ Main symptom at presentation } \\
\hline Abdominal pain & 19 & $(79.1)$ & 58.3 & 91.7 \\
\hline Inability to pass gas/stool & 3 & $(12.5)$ & 4.2 & 33.3 \\
\hline Intraabdominal mass & 1 & $(4.16)$ & 0.0 & 12.5 \\
\hline Menorrhagia & 1 & $(4.16)$ & 0.0 & 12.5 \\
\hline \multicolumn{5}{|l|}{ Preoperative clinical diagnoses } \\
\hline Acute appendicitis & 12 & (50) & 29.2 & 70.8 \\
\hline Appendix tumor & 3 & $(12.5)$ & 6.5 & 25.0 \\
\hline Pelvic mass & 3 & $(12.5)$ & 0.0 & 29.2 \\
\hline Pseudomyxoma peritonei & 2 & $(8.33)$ & 0.0 & 12.5 \\
\hline Colon tumor & 1 & $(4.16)$ & 0.0 & 12.5 \\
\hline Brid ileus & 1 & $(4.16)$ & 0.0 & 12.5 \\
\hline Plastron appendicitis & 1 & $(4.16)$ & 0.0 & 12.5 \\
\hline Appendix mucocele & 1 & $(4.16)$ & 0.0 & 12.5 \\
\hline \multicolumn{5}{|l|}{ Preoperative imaging diagnoses } \\
\hline Acute appendicitis & 7 & $(29.1)$ & 12.5 & 50.0 \\
\hline Acute perforated appendicitis & 5 & $(20.8)$ & 4.2 & 37.5 \\
\hline Pelvic mass & 3 & $(12.5)$ & 0.0 & 25.0 \\
\hline Appendix tumor & 3 & $(12.5)$ & 0.0 & 29.2 \\
\hline Plastron appendicitis & 2 & $(8.33)$ & 0.0 & 20.8 \\
\hline Pseudomyxoma peritonei & 2 & $(8.33)$ & 0.0 & 20.8 \\
\hline Colon tumor & 1 & $(4.16)$ & 0.0 & 12.5 \\
\hline Appendix mucocele & 1 & $(4.16)$ & 0.0 & 12.5 \\
\hline
\end{tabular}

postoperative period. In one patient, the surgical margin was positive with no extra-appendix spread. Surgical margin positivity was detected in one patient with appendix spread. No recurrence was detected in the follow-up of these two patients. Five patients had negative surgical margins, but non-appendix spread. On evaluations after discharge, four patients (16.6\%) had high tumor marker carcinoembryonic antigen (CEA) values. Surgical outcomes are summarized Table 3.

The mean (median) postoperative follow-up period of the patients was $31.25 \pm 23.9$ (27) (range 1-90), 1 -year survival was $91.6 \%$, and 5 -year survival was $83.3 \%$ for six patients who had the operation 5 years ago. Recurrence was detected in three patients during the follow-up period. Follow-up and survival characteristics of the patients are summarized in Table 4.Overall survival time was $35.18 \pm 4.94$ (25.48-44.88) months and disease-free survival time was $32.69 \pm 4.71$ (23.44-41.93) months, as shown in Table 5 and Figures 1 and 2.

\section{Discussion}

In the literature, it is reported that the prevalence of mucinous neoplasm is as low as $0.3 \%$ and most of the studies on this subject are based on case reports. ${ }^{3}$ Lowgrade appendiceal mucinous neoplasms are more common tumors in the middle-aged and female patients. ${ }^{5}$ In our series, the rate of female patients was $59 \%$ and the mean age was 56.4, in accordance with the literature. LAMN may be asymptomatic, but it is often diagnosed by chance or manifests with symptoms of appendicitis. In our series, $79 \%$ of patients presented with abdominal pain. It was reported by Carr et al that $32 \%$ of patients with appendiceal neoplasm were diagnosed with acute appendicitis and $23 \%$ were diagnosed by chance. ${ }^{6}$ In our series, $50 \%$ of patients were diagnosed with acute appendicitis, while $16.6 \%$ of the patients were diagnosed by chance.

Preoperative diagnosis of mucinous appendix tumors is very important. Preoperative evaluation affects selection of the surgical procedure to avoid complications. The most widely used imaging method for preoperative diagnosis is contrast-enhanced CT imaging. To rule out colorectal neoplasm, patients with suspected appendiceal mucocele are recommended a colonoscopy. Colonoscopy shows a pathognomonic volcano sign that identifies a mass blocking the appendiceal opening with a mucinproducing central crater. ${ }^{7}$

Diagnosis of appendix mucinous neoplasia (AMN) on pathological examination largely depends on the presence of mucin. Appendix mucinous neoplasms are commonly stained positive for CK20 (100\%) and generally negative for CK7 (71\%). Also, AMNs are generally positive for MUC5AC (86\%) and DPC4 (100\%). ${ }^{8,9}$ The diagnosis of low-grade mucinous neoplasm is made with atypical cytology and the presence of any of the following criteria; fibrosis of submucosa, loss of muscularis mucosae, "pushing invasion" (expansile or diverticulum-like growth), undulating or flattened epithelial growth, dissection of acellular mucin in wall, rupture of appendix, mucin and/or cells outside appendix. . $^{24}$

A 3-tiered approach is now used in the current eighth edition of the American Joint Committee on Cancer (AJCC) Staging Manual, where low-grade tumors are classified as grade G1, or well-differentiated, but highgrade tumors are classified as grade G2, or moderately differentiated, and grade G3, or poorly differentiated, based on the absence or presence of signet ring cells, respectively. ${ }^{10}$ In a molecular study by Raghav et al, where genetic mutations of AMNs were examined, COX-2 expression was seen in $61 \%$, KRAS in $55 \%$, PI3K in $17 \%$ and BRAF mutations in $4 \%$ of patients. ${ }^{11}$ In addition, the KRAS mutation was strongly associated with wellor moderately differentiated histology. The clinical application of targeted therapies seems to be a promising strategy in this setting. We did not look for genetic mutations in our patients.

Surgical resection is a potentially curative approach. Accepted treatment includes appendectomy with additional chemotherapy, right hemicolectomy, 
Table 3. Operation Details and Follow-up Results of Patients Undergoing Surgical Procedures

\begin{tabular}{|c|c|c|c|c|}
\hline \multirow{2}{*}{ Variable } & \multirow{2}{*}{$\mathbf{N}$} & \multirow{2}{*}{$(\%)$} & \multicolumn{2}{|c|}{ 95\% Confidence Interval } \\
\hline & & & Lower & Upper \\
\hline \multicolumn{5}{|l|}{ Type of admission } \\
\hline Emergency & 16 & $(66.7)$ & 45.8 & 83.3 \\
\hline Elective & 8 & $(33.3)$ & 16.7 & 54.2 \\
\hline \multicolumn{5}{|l|}{ Surgical procedure } \\
\hline Appendectomy only & 14 & $(58.3)$ & 37.5 & 79.2 \\
\hline Total abdominal hysterectomy + oophorectomy + appendectomy & 4 & $(16.7)$ & 4.2 & 33.3 \\
\hline Right hemicolectomy & 1 & $(4.2)$ & 0.0 & 12.5 \\
\hline Partial colon resection + appendectomy & 2 & (8.3) & 0.0 & 20.8 \\
\hline Partial caecum resection + appendectomy & 1 & $(4.2)$ & 0.0 & 12.5 \\
\hline Total colectomy + omentectomy & 1 & $(4.2)$ & 0.0 & 12.5 \\
\hline Appendectomy + omentectomy & 1 & $(4.2)$ & 0.0 & 12.5 \\
\hline \multicolumn{5}{|l|}{ Intraoperative findings } \\
\hline Acute appendicitis & 7 & $(29.1)$ & 12.5 & 50.0 \\
\hline Pseudomyxoma peritonei & 4 & $(16.6)$ & 4.2 & 33.3 \\
\hline Appendiceal mass & 4 & $(16.6)$ & 4.2 & 33.3 \\
\hline Perforated appendicitis & 3 & $(12.5)$ & 0.0 & 29.2 \\
\hline Pelvic mass & 2 & $(8.33)$ & 0.0 & 20.8 \\
\hline Mucocele & 2 & $(8.33)$ & 0.0 & 20.8 \\
\hline Right colon tumor & 1 & $(4.16)$ & 0.0 & 12.5 \\
\hline Plastron appendicitis & 1 & $(4.16)$ & 0.0 & 12.5 \\
\hline \multicolumn{5}{|l|}{ Intraoperative complication } \\
\hline Spleen injury & 1 & $(4.16)$ & 0.0 & 12.5 \\
\hline Caecum perforation & 1 & $(4.16)$ & 0.0 & 12.5 \\
\hline \multicolumn{5}{|l|}{ Postoperative complication } \\
\hline Wound site infection & 2 & $(8.33)$ & 0.0 & 20.8 \\
\hline Pneumonia & 1 & $(4.16)$ & 0.0 & 12.5 \\
\hline \multicolumn{5}{|l|}{ 30-day Readmission } \\
\hline Wound site infection & 2 & $(8.33)$ & 0.0 & 20.8 \\
\hline \multicolumn{5}{|l|}{ Pathological evaluation } \\
\hline Positive appendectomy resection margins & 2 & $(8.33)$ & 0.0 & 20.8 \\
\hline Extra appendiceal dissemination & 6 & (25) & 8.3 & 41.7 \\
\hline Variable & \multicolumn{2}{|c|}{ Mean \pm SD (Min-Max $)$} & & \\
\hline Operation time (min) & 73.75 & $1-180)$ & 61.5 & 87.2 \\
\hline Postoperative hospitalization time & 7.4 & $-31)$ & 4.5 & 10.6 \\
\hline
\end{tabular}

performing a partial colectomy with debulking, or even palliative resection. In the treatment of select eligible patients, cytoreductive surgery (CRS) and hyperthermic intraperitoneal chemotherapy provide long-term survival. The combined treatment modality including CRS and hyperthermic intraperitoneal chemotherapy has led to a 5 -year survival ranging from $5 \%$ to $100 \%$ in lowgrade disease, and a survival ranging from 0 to $65 \%$ for high-grade disease. ${ }^{2,4,12-17}$ Surgical treatment of LAMN, with peritoneal mucin shedding, is controversial. The published literature shows that there is a significant prognostic difference between acellular and cellular mucin. Accordingly, it is recommended in population- based studies to use CRS for relatively early lesions of localized cellular mucin shedding. If treated only with appendectomy or right hemicolectomy, the overall 3-, 5-, 7- and 10-year survival (OS) rates for LAMN are $100 \%$, $86 \%, 60 \%$ and $45 \%$, respectively. ${ }^{9,18}$ In our series, we performed appendectomy in 14 patients, total abdominal hysterectomy + oophorectomy + appendectomy in 5 patients, and colon resections with appendectomy in 5 patients. In our series, 1-year survival was $91.6 \%$ in patients treated with appendectomy or right hemicolectomy, and survival was $83.3 \%$ in patients on 5 -year follow-up.

González-Moreno and Sugarbaker recommend using the sentinel lymph node approach to determine if right 
Table 4. Follow-up and Survival Characteristics of the Patients

\begin{tabular}{|c|c|c|c|c|}
\hline \multirow{2}{*}{ Variable } & \multirow{2}{*}{$\mathbf{N}$} & \multirow{2}{*}{$(\%)$} & \multicolumn{2}{|c|}{$95 \%$ Confidence Interval } \\
\hline & & & Lower & Upper \\
\hline \multicolumn{5}{|l|}{ Tumor Marker } \\
\hline Elevated & 4 & $(16.6)$ & 4,2 & 33,3 \\
\hline \multicolumn{5}{|l|}{ Survival } \\
\hline 1-Year & 22 & $(91.6)$ & 79.2 & 100.0 \\
\hline 5-Year & 6 & $(25)$ & 4.2 & 33,3 \\
\hline Recurrence & 3 & $(12.5)$ & 0.0 & 29,2 \\
\hline Disease-free survival & 18 & $(75)$ & 66.7 & 95,8 \\
\hline Exitus & 4 & $(16.6)$ & 4.2 & 33,3 \\
\hline Variable & \multicolumn{4}{|c|}{ Mean \pm SD (median) (Min-Max) } \\
\hline Postoperative Follow-up Duration & 31.2 & $(1-90)$ & 21.67 & 41.20 \\
\hline
\end{tabular}

Table 5. Overall and Disease-Free Survival

\begin{tabular}{ll}
\hline Overall survival, Mean \pm SD $($ Min-Max) & $35.18 \pm 4.94(25.48-44.88)$ \\
Disease-free survival, Mean \pm SD (Min-Max) & $32.69 \pm 4.71(23.44-41.93)$ \\
\hline
\end{tabular}

hemicolectomy is appropriate. They do not recommend right hemicolectomy in the absence of metastatic disease on frozen examination of sentinel lymph nodes in the appendix mesentery along the appendix artery. ${ }^{19}$ Pahlavan and Kanthan defined similar criteria for right hemicolectomy: (i) the degree of cellular undifferentiation, (ii) increased mitotic activity, (iii) involvement of the base of the appendix, (iv) lymph node metastasis, or $(v)$ having a tumor size greater than $2 \mathrm{~cm}^{18}$. Open surgery is recommended instead of a laparoscopic approach for resection. When making a decision about the approach, it should aim to minimize the rupture of the appendix mucocele. During the operation, it is necessary to take care that the cyst rupture does not happen and cyst fluid does not leak. If mucocele is large and resection is difficult, open surgery should be preferred. However,

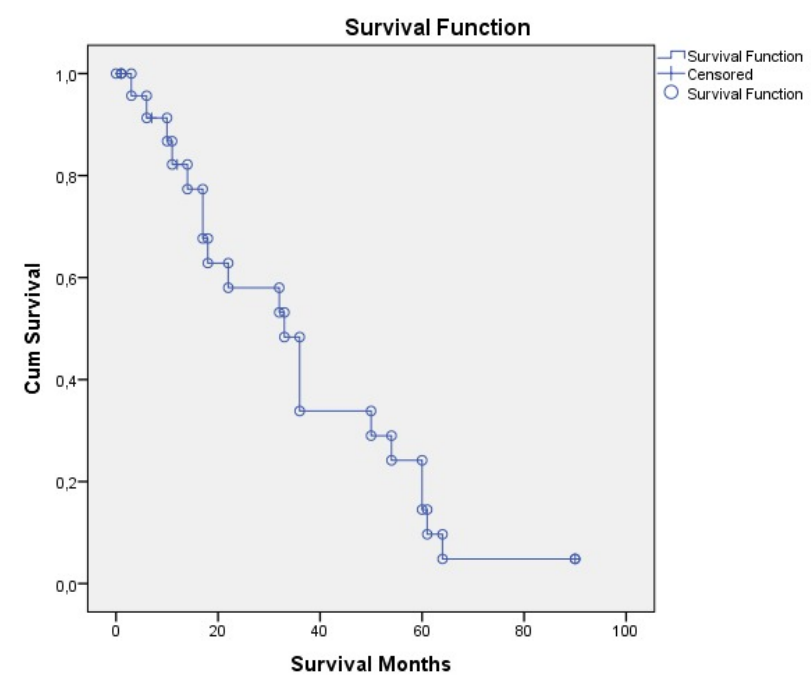

Figure 1. Overall Survival.

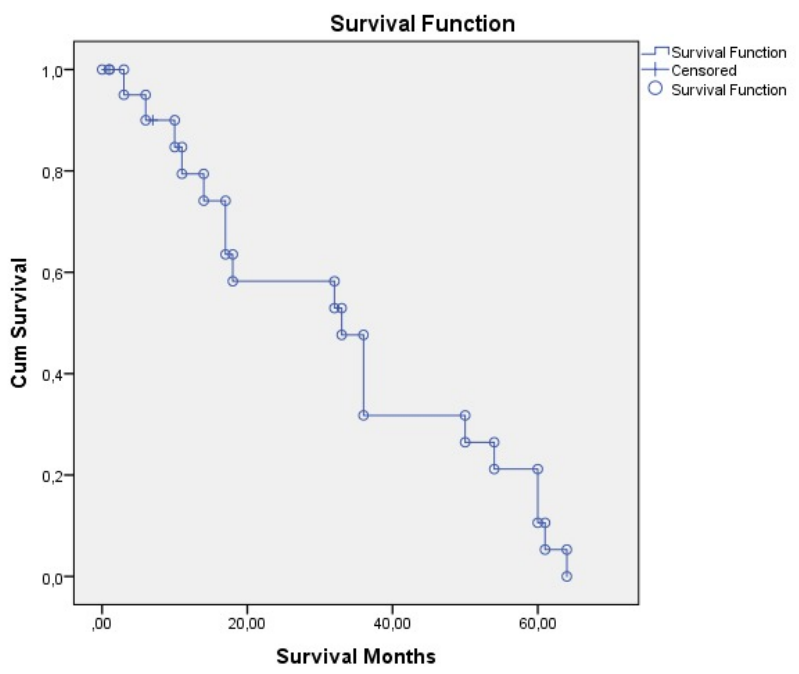

Figure 2. Disease-Free Survival.

there is controversy in the literature when it comes to comparing the advantages and disadvantages of open versus laparoscopic approaches. ${ }^{7,20}$

In our series, we performed open surgery on our patients. In one case where we started the operation laparoscopically with a preliminary diagnosis of acute appendicitis, we switched to open surgery in order not to perforate the appendix mucocele. Cases can be identified by detecting the tumor in pathology after an appendectomy performed with the preliminary diagnosis of acute appendicitis, or by evaluating a frozen section with suspicion of a preoperative tumor. Iatrogenic or spontaneous rupture of appendix mucinous tumors causes the spread of the gelatinous material to the peritoneum, leading to PMP. The presence of PMP is reported to be associated with long-term morbidity and mortality. There 
are also studies showing that it is associated with a decrease in survival rate. ${ }^{1,21}$ In the literature, it is reported that the rate of recurrence was between 33\%-75\% in the presence of periappendicular mucin..$^{12,22,23}$ In our series, six patients had extra-appendiceal dissemination as intraoperative findings and four patients had PMP. Recurrence occurred in two patients in our series. In the literature, it has been reported that the positivity of resection margin is not effective in determining recurrence, so it does not provide any additional clinical benefit in the follow-up of right hemicolectomy in these patients. ${ }^{24,25}$ In a study conducted by Arnason et al, it was observed that there was no residual tumoral tissue in the caecum of patients who were re-operated due to the presence of a positive appendix margin. The possible explanation for this is that appendectomies often have a stapler resection margin and the tissue indicated as margin is not actually a real surgical margin. ${ }^{24}$ In our series, the resection limits were positive in two patients; we did not perform right hemicolectomy due to the above reason.

When it comes to low-grade well-differentiated mucinous tumors, adjuvant chemotherapy is not recommended and should be considered only in certain situations, where the cancer exhibits invasive features such as lymphovascular or lymph node involvement or has mixed-type histology. ${ }^{9}$ Although follow-up times are not determined by strict criteria, a minimum 5-year follow-up is recommended in patients with mucinous appendiceal neoplasm. During follow-up, annual abdominopelvic computed tomography can be followed by CEA, CA 19-9 measurements. There are reported cases whose local recurrence was detected on CT performed within 1 year, who underwent complementary surgery. ${ }^{15-17}$ The average follow-up period in our series was 31.25 months. Increased tumor marker levels in literature were associated with recurrence and associated colorectal cancer. It should be remembered that $11 \%-20 \%$ of patients with colon cancer have accompanying appendix mucocele. ${ }^{26,27}$ In our series, tumor markers were elevated in four patients, but none of our patients had concomitant colorectal malignancies.

In conclusion, appendix mucinous neoplasms appear as rare appendix masses. Clinically, this tumor can cause nonspecific symptoms and usually presents with acute appendicitis. Detailed preoperative evaluation of appendicular masses has an important place in the choice of surgical technique. Care should be taken to ensure that the AMN lesion is not perforated in patients who are operated on with a preliminary diagnosis of acute or plastron appendicitis. PMP, which may develop as a result of perforation, is associated with recurrence and decreased survival. One of the limitations of our study is that it had a retrospective design, and the number of patients was small. Considering the slow course of these low-grade neoplasms, it will be beneficial if studies with longer follow-up periods are conducted to better evaluate the risk of peritoneal recurrence and its impact on survival.

\section{Authors' Contribution}

UT, MG conceiving, designing and editing the manuscript. UT, MA, MG manuscript writing. ABO, ES, MG, KD contributing to logical interpretation and presentation of the results. MA, ES, review and final approval of the manuscript.

\section{Conflict of Interest Disclosures}

None.

\section{Ethical Statement}

Ethics Committee of Erciyes University Faculty of Medicine received the approval dated 22.05.2019 and numbered 20194/08.

\section{References}

1. Smeenk RM, van Velthuysen ML, Verwaal VJ, Zoetmulder FA. Appendiceal neoplasms and pseudomyxoma peritonei: a population based study. Eur J Surg Oncol. 2008;34(2):196201. doi: 10.1016/j.ejso.2007.04.002.

2. Carr NJ, Sobin LH. Adenocarcinoma of the appendix. In: Bosman FT, Carnerio F, Hruban RH, Theise ND, eds. WHO Classifications of Tumors of the Digestive System. 4th ed. Lyon: World Health Organization; 2010. p. 122-5.

3. Misdraji J, Yantiss RK, Graeme-Cook FM, Balis UJ, Young RH. Appendiceal mucinous neoplasms: a clinicopathologic analysis of 107 cases. Am J Surg Pathol. 2003;27(8):1089103. doi: 10.1097/00000478-200308000-00006.

4. Carr NJ, Cecil TD, Mohamed F, Sobin LH, Sugarbaker PH, González-Moreno S, et al. A consensus for classification and pathologic reporting of pseudomyxoma peritonei and associated appendiceal neoplasia. Am J Surg Pathol. 2016;40(1):14-26. doi: 10.1097/pas.0000000000000535.

5. Sugarbaker PH. Peritonectomy procedures. Ann Surg. 1995;221(1):29-42. doi: 10.1097/00000658-19950100000004.

6. Carr NJ, McCarthy WF, Sobin LH. Epithelial noncarcinoid tumors and tumor-like lesions of the appendix. A clinicopathologic study of 184 patients with a multivariate analysis of prognostic factors. Cancer. 1995;75(3):75768. doi: 10.1002/1097-0142(19950201)75:3<757::aidcncr2820750303>3.0.co;2-f.

7. Motsumi MJ, Motlaleselelo P, Ayane G, Sesay SO, Valdes JR. A case report of a giant appendiceal mucocele and literature review. Pan Afr Med J. 2017;28:106. doi: 10.11604/ pamj.2017.28.106.13832.

8. Ji H, Isacson C, Seidman JD, Kurman RJ, Ronnett BM. Cytokeratins 7 and 20, Dpc4, and MUC5AC in the distinction of metastatic mucinous carcinomas in the ovary from primary ovarian mucinous tumors: Dpc4 assists in identifying metastatic pancreatic carcinomas. Int J Gynecol Pathol. 2002;21(4):391-400. doi: 10.1097/00004347200210000-00009.

9. Shaib WL, Assi R, Shamseddine A, Alese OB, Staley C 3rd, Memis B, et al. Appendiceal mucinous neoplasms: diagnosis and management. Oncologist. 2017;22(9):110716. doi: 10.1634/theoncologist.2017-0081 .

10. Overman MJ, Asare EA, Compton CC, Hanna NN, Kosinski LA, Washington MK, et al. Appendix — carcinoma. In: Amin M, ed. AJCC Cancer Staging Manual. 8th ed. Chicago, IL: Springer; 2017. p. 237-50.

11. Raghav KP, Shetty AV, Kazmi SM, Zhang N, Morris J, Taggart $\mathrm{M}$, et al. Impact of molecular alterations and targeted therapy in appendiceal adenocarcinomas. Oncologist. 
2013;18(12):1270-7. doi: 10.1634/theoncologist.2013-0186.

12. Paşaoğlu E, Dursun N. The current approach to appendiceal mucinous neoplasms and pseudomyxoma peritonei. J Curr Pathol. 2018;2(2):46-56. doi: 10.5146/jcpath.2018.26.

13. Eze O, Jones R, Montgomery E. A practical approach for diagnosis of appendiceal mucinous neoplasms. Diagn Histopathol. 2017;23(12):530-5. doi: 10.1016/j. mpdhp.2017.11.004.

14. Lynch K, Cho S, Andres R, Knight J, Con J. Pre-operative identification and surgical management of the appendiceal mucocele: a case report. W V Med J. 2016;112(4):28-30.

15. Mastoraki A, Sakorafas G, Vassiliu P, Contopoulou C, Arkadopoulos N. Mucocele of the appendix: dilemmas in differential diagnosis and therapeutic management. Indian J Surg Oncol. 2016;7(1):86-90. doi: 10.1007/s13193-0150463-3.

16. Lansom J, Alzahrani N, Liauw W, Morris DL. Cytoreductive surgery and hyperthermic intraperitoneal chemotherapy for pseudomyxoma peritonei and appendix tumours. Indian J Surg Oncol. 2016;7(2):166-76. doi: 10.1007/ s13193-015-0478-9.

17. Padmanaban V, Morano WF, Gleeson E, Aggarwal A, Mapow BL, Stein DE, et al. Incidentally discovered lowgrade appendiceal mucinous neoplasm: a precursor to pseudomyxoma peritonei. Clin Case Rep. 2016;4(12):11126. doi: $10.1002 / \mathrm{ccr} 3.694$.

18. Pahlavan PS, Kanthan R. Goblet cell carcinoid of the appendix. World J Surg Oncol. 2005;3:36. doi: 10.1186/14777819-3-36.

19. González-Moreno S, Sugarbaker PH. Right hemicolectomy does not confer a survival advantage in patients with mucinous carcinoma of the appendix and peritoneal seeding. Br J Surg. 2004;91(3):304-11. doi: 10.1002/bjs.4393.

20. Calişkan K, Yildirim S, Bal N, Nursal TZ, Akdur AC,
Moray G. Mucinous cystadenoma of the appendix: a rare cause of acute abdomen. Ulus Travma Acil Cerrahi Derg. 2008;14(4):303-7.

21. Xiao J, Li P, Liu W. Analysis of Clinical Characteristics of Low-Grade Appendiceal Mucinous Neoplasm (LAMN): A Retrospective Cohort Study of 51 LAMN Patients. J Invest Surg. 2021;34(7):721-727. doi:10.1080/08941939.2019.1695 986

22. Pai RK, Beck AH, Norton JA, Longacre TA. Appendiceal mucinous neoplasms: clinicopathologic study of 116 cases with analysis of factors predicting recurrence. Am J Surg Pathol. 2009;33(10):1425-39. doi: 10.1097/ PAS.0b013e3181af6067.

23. Yantiss RK, Shia J, Klimstra DS, Hahn HP, Odze RD, Misdraji J. Prognostic significance of localized extraappendiceal mucin deposition in appendiceal mucinous neoplasms. Am J Surg Pathol. 2009;33(2):248-55. doi: 10.1097/PAS.0b013e31817ec31e.

24. Arnason T, Kamionek M, Yang M, Yantiss RK, Misdraji J. Significance of proximal margin involvement in low-grade appendiceal mucinous neoplasms. Arch Pathol Lab Med. 2015;139(4):518-21. doi: 10.5858/arpa.2014-0246-OA.

25. Foster JM, Gupta PK, Carreau JH, Grotz TE, Blas JV, Gatalica $\mathrm{Z}$, et al. Right hemicolectomy is not routinely indicated in pseudomyxoma peritonei. Am Surg. 2012;78(2):171-7.

26. Shimizu T, Shimizu M, Kawaguchi K, Yomura W, Ihara Y, Matsumoto T. Mucinous cystadenoma of the appendix with raised serum carcinoembryonic antigen concentration: clinical and pathological features. J Clin Pathol. 1997;50(7):613-4. doi: 10.1136/jcp.50.7.613.

27. Abuoğlu H, Yıldı MK, Kaya B, Odabaşı M. Clinicopathological analysis of patients operated for appendiceal mucocele. Ulus Travma Acil Cerrahi Derg. 2017;23(3):230-4. doi: 10.5505/tjtes.2016.30276. 